\title{
RELATIONSHIP BETWEEN VENTRICULAR ASYNCHRONY AND QRS DURATION IN PATIENTS WITH LEFT VENTRICULAR SYSTOLIC DYSFUNCTION
}

\author{
AKHTERUZZAMANM M ${ }^{1}$, RAHMAN A ${ }^{2}$, RAHMAN M A ${ }^{3}$, AMIN $\mathrm{R}^{4}$, MIAH MNA ${ }^{5}$, KHAN A. R ${ }^{6}$, CHOWDHURY \\ T.A ${ }^{7}$, HOSSAIN A ${ }^{8}$, KASHEM M.A ${ }^{9}$
}

\begin{abstract}
:
Background: There are variable degree of asynchrony in end-stage heart failure patients with varying QRS widths and LV function. The study was based on evaluation of relationship between ventricular asynchrony and QRS duration in patients with left ventricular systolic dysfunction in Bangladesh.

Methods and materials: This work was carried out in the department of cardiology, Sir Salimullah Medical College, Mitford Hospital, Dhaka from September 2010 to August 2011. 103 patients were selected on the basis of inclusion and exclusion criteria as the study sample. After evolution by history, clinical examination and echocardiography and Tissue Doppler imaging were done in all selected patients by two cardiologists who were blinded to ECG report. Both interventricular \& intraventricular conduction delay were measured in all patients of three groups.

Result: Interventricular asynchrony by measuring interventricular mechanical delay (IVMD) was greater

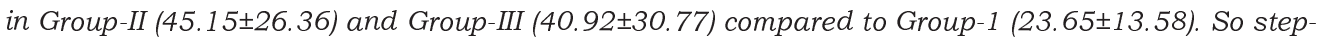
wise increase in IVMD was noted over three groups \& it was statistically significant $(P<0.001)$. But Linear regression demonstrated weak relation between $Q R S$ duration $\& I V M D(Y=0.314 x+7.61, n=103$, $r=0.372, p=0.000$ ) though widely scattered data around the identity line was observed. Intraventricular asynchrony by measuring Septal to post wall motion delay (SPWMD) in msec was also lowest in narrow $Q R S$ group compared to others $(P>0.05)$. Linear regression failed to find any relation between $Q R S$ duration and Septal-to-posterior wall delay among the patients $(r=0.199, p=0.044)$. Though the magnitude of Lateral-to-Septal delay (LSD) was gradually increased among the groups but it was not significant $(P>0.05)$. No relation was found between $Q R S$ duration and Lateral-to-Septal delay $(r=0.152, p=0.126)$. Using the cut off value $60 \mathrm{~ms}$, this study found $65.4 \%$ patients of wide QRS group (>150ms) had significant Intraventricular asynchrony \& $31 \%$ patients of narrow QRS group showed significant asynchrony.

Conclusion: The main result of this is the QRS width appears to be poorly correlated with the presence of inter-V and intra-LV electromechanical asynchrony. This study also suggest that, interventricular asynchrony may be grossly identified by the presence of a wide QRS on surface ECG but that, more sophisticated imaging techniques are needed to find out Intraventricular asynchrony.
\end{abstract}

Key words: Ventricular asynchrony, QRS duration, Left ventricular systolic dysfunction.

\section{Introduction:}

Heart failure due to left ventricular systolic dysfunction (LVSD) is a common, costly, disabling and life-threatening condition. Around 1, 20,000 hospital admissions per year are due to LVSD in the $\mathrm{UK}^{1}$. The survival rate of LVSD from the time of diagnosis is $67 \%$ at 1 year and $24 \%$ at 3 years. As LVSD often carries a worse prognosis than several of the common cancers, it is important that patients who present to their family physician with symptoms suggestive of LVSD are identified and offered appropriate treatment ${ }^{2}$.

Heart failure can be classified into two broad categories: $\mathrm{HF}$ with LV systolic dysfunction and $\mathrm{HF}$ with preserved systolic function termed diastolic

1. Registrar, Department of Cardiology, Bangladesh Medical College Hospital, Dhaka

2. Registrar, Department of Neurology, Sir Salimullah Medical College Mitford Hospital, Dhaka

3. Professor, Department of Cardiology, National Institute of Cardiovascular Diseases, Dhaka.

4. Associate Professor, Department of Medicine, Dhaka Medical College, Dhaka

5. Assistant Professor, Department of Medicine, Sir Salimullah Medical College, Dhaka

6. Assistant Professor, Department of Cardiology, Sir Salimullah Medical College, Dhaka

7. Assistant Professor, Department of Cardiology, Sir Salimullah Medical College, Dhaka

8. Department of Neurology, Dhaka Medical College Hospital, Dhaka

9. Department of Medicine, Sir Salimullah Medical College Mitford Hospital, Dhaka

Bangladesh J Medicine 2012; 23 : 52-58 
dysfunction. The systolic dysfunction means inability of $\mathrm{LV}$ to eject blood into high-pressure aorta that means reduced ejection fraction. The term diastolic dysfunction means that the ventricle cannot accept blood at its usual low pressure ventricular filling is slow, delayed, or incomplete unless atrial pressure increases consequently ${ }^{3}$.

LV dysfunction is characterized by a change in preload and after load, decrease in myocardial contractility, and increase in diastolic filling pressures ${ }^{4}$. Changes in preload and after load have been characterized by LV remodeling with an increase in the size of left ventricle and a change in LV geometry. Generally, LV diastolic wall stress is used as parameter for preload and LV end-systolic or mean-systolic wall stress as measure for after load. More commonly, the volume-derived contractility parameters are used, such as cardiac index, stroke work index, or preload recruit able stroke work. The most useful parameter in daily practice is the LV ejection fraction, which is the parameter used most frequently for differentiating between systolic and diastolic dysfunction. An ejection fraction of more than 50 percent is considered to be normal, an ejection fraction between 35 to 50 percent is moderately depressed, and an ejection fraction below 35 percent represents a severely depressed systolic pump function. Many of the large clinical heart failure trials are based on these definitions and different therapeutic interventions are dependent on the LVEF, such as the implantation of an ICD \& Biventricular pacing ${ }^{5}$.

In the developing countries like Bangladesh with increase of life expectancy from 41 to 61 years and control of common infectious diseases and improvement of life style, cardiovascular diseases as well as mortality caused by it is showing an increasing trends ${ }^{6}$. A hospital based cross sectional study was done at a tertiary cardiac hospital in Dhaka city. Hospital medical records of 14,009 patients admitted between January 2005 and August 2006 were reviewed and 1970 patients with the diagnosis of Heart Failure were identified. Relevant etiological information and socio demographic data were abstracted from the hospital record files. The mean age of hospitalized HF patients is remarkably lower than other related studies done abroad. The single most common etiology for $\mathrm{HF}$ is ischemic heart disease in this population. Hypertension is the most common risk factor ${ }^{7}$.

Another study in National institute of Cardiovascular Diseases, Dhaka, Bangladesh showed that heart failure is most commonly prevalent in the $50-59$ years age group. The commonest cause of heart failure was ischemic heart disease (44.97\%) followed by hypertension $(22.96 \%)$ and valvular heart disease $(21 \%)$. Among heart failure patient $67 \%$ had left heart failure and $33 \%$ had right heart failure ${ }^{8}$.

There is however no large study which has analyzed the true prevalence and degree of asynchrony in endstage heart failure patients with varying QRS widths and LV function. We still do not know whether there is a link between interventricular and Intraventricular asynchrony, to what extent they are related to QRS morphology, to etiology of the disease or to the degree of left ventricular dysfunction. Focusing these issues is not only a matter of pathophysiological relevance but it is also important to solve the clinical problem of the identification of patients most likely to respond to cardiac resynchronization therapy. The present study was therefore planned to assess the relationship between QRS duration on surface ECG and ventricular asynchrony in large group of patients with both narrow and wide QRS complexes and varying degree of LV dysfunction using noninvasive 2D, M-mode echocardiogram, pulse-wave Doppler, and pulse-wave tissue Doppler imaging.

\section{Methods:}

It was a Cross sectional study in the Department of Cardiology, Sir-Salimullah Medical College Mitford Hospital, Dhaka from September 2010 to August 2011. Total103 consecutive patients with left ventricular systolic dysfunction \& symptomatic (NYHA class IIIIV) on the basis of the inclusion and exclusion criteria were studied. Patients of acute myocardial infarction were excluded by ECG and biomarkers. Inclusion criteria: Patients above 18 years of either sex with symptomatic heart failure (NYHA Class III or IV), etiology due to Ischeamic Cardiomyopaty or non Ischeamic Dilated Cardiomyopathy and LVEF $<40 \%$ by $2 \mathrm{D}$ echocardiogram. Exclusion criteria: Patients with non sinus rhythm, Predominant diastolic dysfunction \& vulvular heart disease, previous pacemaker implantation, acute coronary syndrome (ACS) in last three months and acute heart failure. Based on QRS duration the selected patients were then grouped as Group-1 narrow QRS group (QRS width $<120 \mathrm{~ms}$ ), Group-II intermediate QRS group (QRS width 120-150ms) \& Group-III wide QRS group (QRS width $>150 \mathrm{~ms}$ ). After proper evaluation by history and clinical examination ECG and Echocardiography were done by two cardiologists. Cardiologists who done the echocardiography were blinded to the electrocardiographic characteristics and also without knowledge of the clinical status of the patient. 
Assessment of Interventricular Asynchrony: The aortic pre-ejection time was measured from the beginning of QRS complex to the beginning of the aortic flow velocity curve (Q-AV) recorded by pulsed-wave (PW) Doppler in apical 5-chamber view. The pulmonary preejection time was measured from the beginning of QRS complex to the beginning of the pulmonary flow velocity curve (Q-PV) recorded in the left parasternal view. The difference between the two values determined the interventricular mechanical delay (IVMD); an IVMD>40 ms was considered as the cutoff value for interventricular asynchrony $9,10,11$.

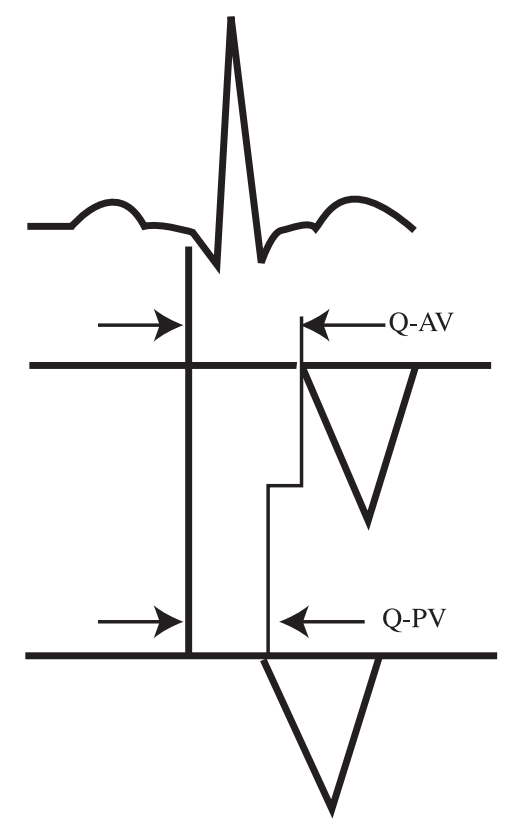

Fig. 1. Assessment of Interventricular mechanical delay by Doppler echocardiography. $(Q-A V=Q$ to Aortic flow, $Q-P V=Q$ to pulmonary flow) IVMD is calculated by subtracting $Q-P V$ from $Q-A V$

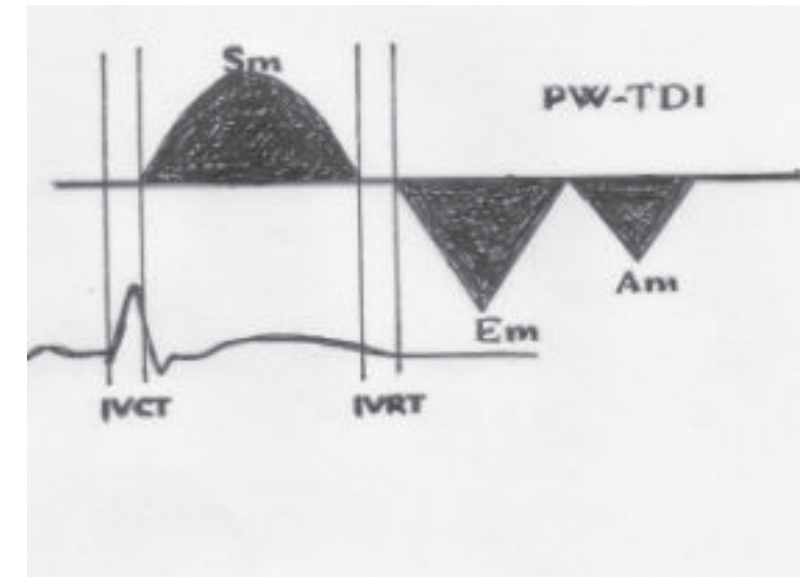

Fig: 2 This diagram shows myocardial velocity curve by Tissue Doppler Imaging. Sm=systolic velocity. Em=early diastolic velocity, Am= Late diastolic velocity, IVCT=Isovolumetric contraction time, IVRT= Isovolumetric relaxation time 04 )
Assessment of Intraventricular Asynchrony: Intraventricular asynchrony promotes electromechanical delays between the walls of the left ventricle, and there are several ways to analyze it through an echocardiography. a) Septal to posterior wall motion delay (SPWMD) :This was measured as the shortest interval between maximum Posterior displacement of septum and maximum anterior displacement of LV posterior wall on M-mode in a parasternal short axis view at papillary muscle level and was considered significant when it was e" 130 msec. ${ }^{12,9}$. b) Lateral-to-septal delay (LSD): Spectral pulsed-wave tissue Doppler imaging (PW-TDI) was applied online by placing the sample volume in the middle of the basal portions of the LV septal and lateral walls in an apical four chamber view. Gain and filter settings were adjusted to allow for a clear tissue signal. Myocardial tissue velocities were recorded end-expiratory at a sweep speed of $100 \mathrm{~mm} /$ s (Fig-2) and the time to start of the QRS complex to peak systolic velocity (TP) of septal and lateral wall were measured ${ }^{13}$. Each parameter was measured for three consecutive beats \& was averaged. Left ventricular asynchrony was defined as a lateral-toseptal delay $(\mathrm{LSD})>60 \mathrm{~ms}$, in accordance with the published data from colour TDI 9, 14. All TDI time intervals were measured by one single observer who was blinded to the patient's data performed.

Data were expressed as mean \pm standard deviation for continuous variables and as frequency and percentages for discrete variables. Descriptive statistics were done by mean, standard deviation, multiple responses \& Cross table. Chi- square test, ANOVA were done in define groups (by QRS complex).Linear regression analysis were performed to determine the relationship between QRS duration and Interventricular, Intraventricular asynchrony .All statistical analysis were performed using SPSS (Statistical Package for Social Sciences), version 16.0 Level of significance was set at .05 and $p$-value $<0.05$ was considered significant.

\section{Results}

Among the 103 heart failure patient majority 36(35\%) were at the age group between 55-65 years, $25(24.3 \%)$ were at the age group between $45-55$ years, $23.3 \%$ aged more than 65 years and only 3 were aged less than 35 years. Mean age was $57.9 \pm 11.9$ (range 23-82 years). Majority of them were male (70.9\%) and rest $29.1 \%$ were female. Male: Female ratio was $2: 1$ 
Table-I

Distribution of the subject by age

\begin{tabular}{lcc}
\hline Age group & Frequency & Percent \\
\hline$<35$ years & 3 & 2.9 \\
35-45 years & 15 & 14.6 \\
45-55 years & 25 & 24.3 \\
$55-65$ years & 36 & 35.0 \\
$>65$ years & 24 & 23.3 \\
\hline Total & 103 & 100.0 \\
\hline
\end{tabular}

Mean age $57.9 \pm 11.9$

\section{Table-II}

Distribution of the subject by risk factors

\begin{tabular}{lcc}
\hline Risk factor & Responses & \\
& $\mathrm{N}$ & Percent of Cases \\
\hline Diabetics & 30 & $32.3 \%$ \\
Hypertension & 46 & $49.5 \%$ \\
Tobacco Smoking & 66 & $71.0 \%$ \\
Dyslipidemia & 39 & $41.9 \%$ \\
Bronchial Asthma & 10 & $10.8 \%$ \\
IHD & 21 & $22.6 \%$ \\
Obesity & 19 & $20.4 \%$ \\
\hline Total & 231 & $248.4 \%$ \\
\hline
\end{tabular}

(**Multiple response observed)
Diabetics was found among the $30(32.3 \%)$ patients, $46(49.5 \%)$ were hypertensive, $66(71.0 \%)$ were tobacco smoker, Dyslipidemia were present among 39(41.9\%) patients, $10(10.8 \%)$ has been suffered from bronchial asthma, $21(22.6 \%)$ had IHD and obesity was common $19(20.4 \%)$ patients.

Interventricular asynchrony (IVMD) was significantly lowest in Group-1 (23.65 \pm 13.58$)$ compared to GroupII (45.15 \pm 26.36$)$ and Group-III (40.92 \pm 30.77$)(\mathrm{P}<0.001)$

Intraventricular asynchrony by measuring Septal to post wall motion delay (SPWMD) in msec was also lowest in narrow QRS group (124 \pm 43.68$)$ compared to intermediate (133 \pm 38.05$)$ and wide QRS $(137 \pm 39.61)$ group. Though mean SPWMD were increased in wide \& intermediate QRS group, but it was not significant $(P>0.05)$. The magnitude of Lateral-to-septal delay (LSD) were gradually increased among the groups

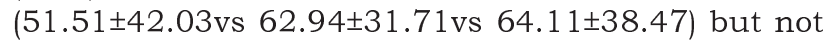
significantly $(\mathrm{P}>0.05)$.

Lateral to Septal delay (LSD) more than $60 \mathrm{~ms}$ were found $18(31 \%)$ among the group where QRS delay less than $120 \mathrm{~ms}$, 9(47.4\%) where QRS delay were between 120-150ms and 17(65.4\%) where QRS delay more than $150 \mathrm{~ms}$.

Among the 47 patient those who have Septal to posterior wall motion delay (SPWMD) (>130ms), $22(37.9 \%)$ among the group where QRS delay less than $120 \mathrm{~ms}, 9(47.4 \%)$ where QRS delay between 120 $150 \mathrm{~ms}$ and $16(61.5 \%)$ where QRS delay more than $150 \mathrm{~ms}$. Interventricular Mechanical delay (IVMD) were found 4(6.9\%) with narrow QRS group (<120ms), $12(63.3 \%)$ with intermediate group and $17(65.4 \%)$ with wide QRS group (>150ms).

Table- III

Comparison of Interventricular \& Intraventricular Asynchrony among three groups

\begin{tabular}{|c|c|c|c|c|}
\hline \multirow[t]{2}{*}{ Asynchrony } & \multicolumn{3}{|c|}{ QRS duration } & \multirow[t]{2}{*}{$P$ value } \\
\hline & $\begin{array}{c}<120 \mathrm{~ms} \\
\mathrm{G}-\mathrm{I}(\mathrm{n}=58)\end{array}$ & $\begin{array}{l}120-150 \mathrm{~ms} \\
\text { G-II }(\mathrm{n}=19) \\
\end{array}$ & $\begin{array}{c}>150 \mathrm{~ms} \\
\text { G-III }(\mathrm{n}=26)\end{array}$ & \\
\hline Interventricular Asynchrony (IVMD) ms & $23.65 \pm 13.58$ & $45.15 \pm 26.36$ & $40.92 \pm 30.77$ & $\mathrm{P}=.000^{\mathrm{S}}$ \\
\hline Intraventricular Asynchrony(SPWMD) ms & $124 \pm 43.68$ & $133 \pm 38.05$ & $137 \pm 39.61$ & $\mathrm{P}=0.379^{\mathrm{NS}}$ \\
\hline Intraventricular Asynchrony(LSD) ms & $51.51 \pm 42.03$ & $62.94 \pm 31.71$ & $64.11 \pm 38.47$ & $\mathrm{P}=0.370^{\mathrm{NS}}$ \\
\hline
\end{tabular}

\# Data were analyzed using ANOVA statistics and were presented as Mean \pm SD.S $=$ significant NS=non significant

Table-IV

Distribution of the subject by different measurement of ventricular conduction delays among three groups

\begin{tabular}{lcccc}
\hline Asynchrony & \multicolumn{2}{c}{ QRS duration } & & Total \\
& $<120 \mathrm{msG}-\mathrm{I}(\mathrm{n}=58)$ & $120-150 \mathrm{msG}-\mathrm{II}(\mathrm{n}=19)$ & $>150 \mathrm{msG}-\mathrm{III}(\mathrm{n}=26)$ & \\
\hline LSD $>60 \mathrm{~ms}$ & $18(31 \%)$ & $9(47.4 \%)$ & $17(65.4 \%)$ & 44 \\
SPWMD $>130 \mathrm{~ms}$ & $22(37.9 \%)$ & $9(47.4 \%)$ & $16(61.5 \%)$ & 47 \\
IVMD $>40 \mathrm{~ms}$ & $4(6.9 \%)$ & $12(63.3 \%)$ & $17(65.4 \%)$ & 33 \\
\hline
\end{tabular}


Table-V

Comparison of 2D \&M-mode echocardiographic characteristics of patients among three groups.

\begin{tabular}{|c|c|c|c|c|}
\hline & \multicolumn{3}{|c|}{ QRS duration } & \multirow[b]{2}{*}{$P$ value } \\
\hline & $<120 \mathrm{~ms} \quad(\mathrm{n}=58)$ & $120-150 \mathrm{~ms}(\mathrm{n}=19)$ & $>150 \mathrm{~ms}(\mathrm{n}=26)$ & \\
\hline $\mathrm{EF}(\%)$ & $28.51 \pm 4.85$ & $27.73 \pm 4.84$ & $26.79 \pm 3.91$ & $0.249^{\mathrm{NS}}$ \\
\hline $\mathrm{EDV}(\mathrm{ml})$ & $148.50 \pm 27.74$ & $163.00 \pm 37.28$ & $181.53 \pm 27.80$ & $0.000^{\mathrm{S}}$ \\
\hline $\mathrm{ESV}(\mathrm{ml})$ & $110.62 \pm 23.04$ & $119.94 \pm 29.57$ & $136.34 \pm 22.50$ & $0.000^{\mathrm{S}}$ \\
\hline LVIDd & $66.51 \pm 7.63$ & $66.05 \pm 6.98$ & $68.50 \pm 8.90$ & $0.005^{\mathrm{S}}$ \\
\hline LVIDs & $53.29 \pm 7.28$ & $53.47 \pm 13.87$ & $59.65 \pm 8.54$ & $0.012^{\mathrm{S}}$ \\
\hline
\end{tabular}

\#Data were analyzed using ANOVA statistics and were presented as

Mean $\pm \mathrm{SD} \mathrm{S}=$ significant $\mathrm{NS}=$ non significant

2D \& M-mode echocardiography findings of patients demonstrate that EDV, ESV, LVIDd \& LVIDs were significantly lowest in narrow complex group (QRS $<120 \mathrm{~ms}$ ) compared to intermediate and wide QRS $(>150 \mathrm{~ms})$ groups $(\mathrm{p}=0.000, \mathrm{p}=0.000, \mathrm{p}=0.005$ and $\mathrm{p}=0.012$ respectively), while ejection fraction was significantly highest in narrow complex group that those in intermediate and wide complex groups $(p=0.249)$

Lateral to septal delay (LSD)

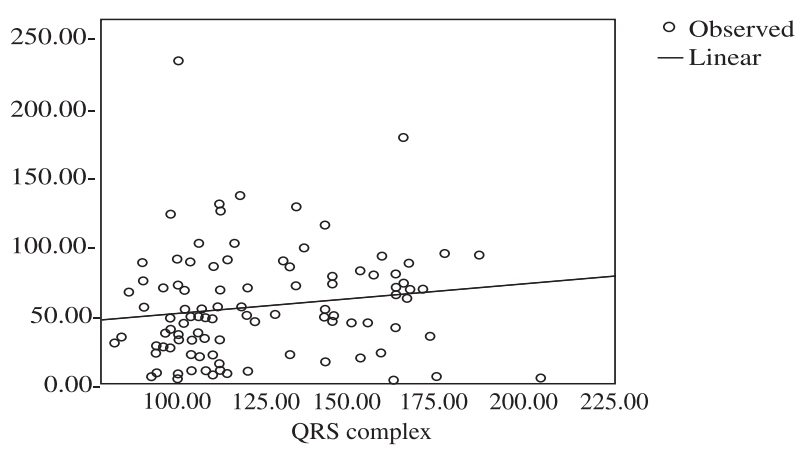

Fig.- 3 Relationship between $Q R S$ duration and Lateralto-Septal (LDS) delay

Linear regression demonstrated no relation between QRS duration and lateral-to-septal (LSD) delay among the patients $(\mathrm{Y}=0.215 \mathrm{x}+29.62, \mathrm{n}=103, \mathrm{r}=0.152, \mathrm{p}=0.126$

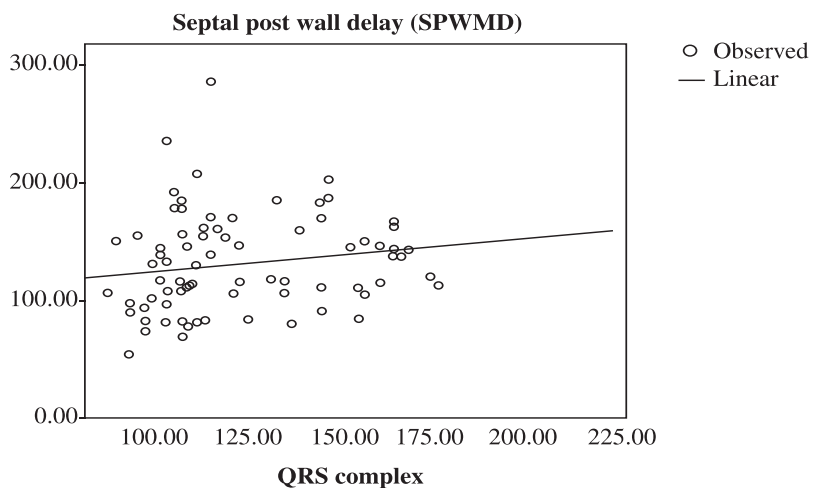

Fig.-4 Relationship between QRS duration and Septalpost wall motion delay (SPWMD)
Linear regression demonstrated no relation between QRS duration and septal-to-posterior delay among the patients $(Y=0.291 x+91.736, n=103, r=0.199$, $\mathrm{p}=0.044)$

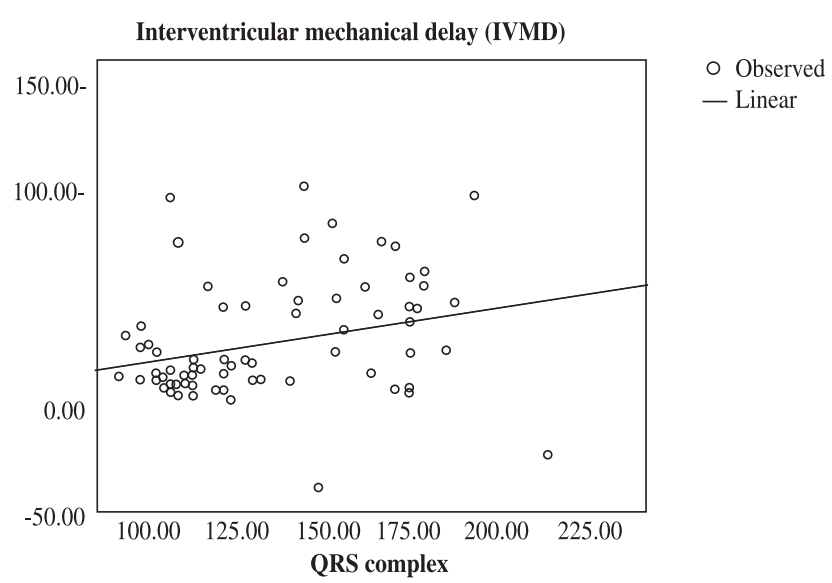

Fig.-5: Relationship between QRS duration and interventricular mechanical delay (IVMD)

Linear regression demonstrated very weekly relation between QRS duration and interventricular mechanical delay among the patients $(\mathrm{Y}=0.314 \mathrm{x}+7.61$, $\mathrm{n}=103, \mathrm{r}=0.372, \mathrm{p}=0.000$ )

\section{Discussion}

Among the 103 patients majority of the subjects with systolic dysfunction were older than 50 years and male $(70.9 \%)$, the mean age was $57.9 \pm 11.9$ years. it is similar to other study done by Bader et al ${ }^{10}$ who found mean ages of heart failure $59 \pm 16$, most patients were male (86\%).In Bangladesh another study by Kabiruzzaman et al described that mean age $(54.1 \pm 15.3)$ of heart failure is lower in our country than abroad ${ }^{7}$.

Smoking was the major risk factor 66(71\%), 46(49.5\%) patients were hypertensive, $21(22 \%)$ patients had previous history of CAD, $30(32.3 \%)$ patients were 
diabetic \& Dyslipidaemia was present about $41.9 \%$ (Table: II). It is similar to other study.

Interventricular asynchrony by measuring interventricular mechanical delay (IVMD) were significantly lowest in Group-1 (23.65 13.58$)$ compared to Group-II (45.15 \pm 26.36$)$ and Group-III (40.92 \pm 30.77$) \quad(\mathrm{P}<0.001) \quad(T a b l e-I I I)$. So significant increase in IVMD was noted over three groups. Again $65.4 \%$ patients of wide QRS(>150 ms) group \& $63.3 \%$ of intermediate QRS group did not show interventricular asynchrony In addition, a small percentage of patients with narrow QRS duration $(<120 \mathrm{~ms})$ also showed interventricular asynchrony(6.9\%)(Table.IV).

This findings were consistent with that of Ghio $(18 \pm 20$ vs $43 \pm 30$ vs $59 \pm 29, \mathrm{p}<.05)$. Ghio also demonstrated $38 \%$ patients of wide QRS group \& $47.6 \%$ of intermediate group failed to show interventricular asynchrony but $11.5 \%$ of narrow QRS group showed significant asynchrony ${ }^{11}$.

Intraventricular asynchrony by measuring Septal to post wall motion delay (SPWMD) in msec was also lowest in narrow QRS group (124 \pm 43.68$)$ compared to intermediate $(133 \pm 38.05)$ and wide QRS $(137 \pm 39.61)$ group. Though mean SPWMD were increased in wide $\&$ intermediate QRS group, but it was not significant $(\mathrm{P}>$.o5) It is similar to study done in India by Kumar \&Goel ${ }^{15}$.

The magnitude of Lateral-to-septal delay (LSD) was gradually increased among the groups $(51.51 \pm 42.03 \mathrm{vs}$ $62.94 \pm 31.71 \mathrm{vs} 64.11 \pm 38.47)$ but not significantly. $(\mathrm{P}>0.05)$ using the cut off value $60 \mathrm{~ms}$, this study found $65.4 \%$ patients of wide QRS (>150ms) group and $47.4 \%$ of intermediate group had significant asynchrony. Majority of patients (69\%) of narrow QRS complex did not exhibit asynchrony, interestingly $31 \%$ showed significant asynchrony. (Table-V) These findings had similarities with the study by Bleeker et al ${ }^{16}$.

Another study by Bader et al, illustrated that the presence of intra-LV (but not inter-V) asynchrony was identified as an independent predictor of severe cardiac events (hazard ratio 3.39, p < 0.0001), independent of the LVEF and QRS width and also showed that patients with a QRS width $<120 \mathrm{~ms}(55 \%$; $\mathrm{n}=57), 56 \%$ presented with major intra-LV asynchrony and $12 \%$ with inter-Vasynchrony ${ }^{10}$.

Mean difference between ejection fraction $(\mathrm{EF})$ and $\mathrm{QRS}$ duration has no significant value $(\mathrm{P}=0.249)$. Left ventricular end diastolic volume (EDV) and end systolic Volume were increased in parallel to QRS duration $(\mathrm{P}<0.001$ (Table-V). LVIDd \& LVIDs were also significantly increased in wide (>150ms) \& intermediate QRS(120-150ms) compared to narrow $\mathrm{QRS}(<120 \mathrm{~ms})$ group $(\mathrm{P}=0.005 \mathrm{P}=0.012)$ These finding had similarities with the study of Bleeker et al ${ }^{16}$.

In this study, among the patients of intraventricuar asynchrony, Linear regression failed to demonstrate any relation between QRS duration and Lateral-toseptal delay $(Y=0.215 x+29.62, n=103, r=0.152$, $\mathrm{p}=0.126)($ Fig-3) Bleeker et al, also showed no relation between them. ( $\mathrm{r}=0.18, \mathrm{NS})$

Also no significant relation existed between QRS duration and septal-to-posterior wall delay. $(Y=0.291 x+91.736, n=103, r=0.199, p=0.044)($ Fig-4) But among the patients of interventricular asynchrony, though widely scattered data Linear regression demonstrated weak relation between $Q R S$ duration IVMD $(\mathrm{Y}=0.314 \mathrm{x}+7.61, \mathrm{n}=103, \mathrm{r}=0.372$, $\mathrm{p}=0.000)$ (Fig-5) which was very much similar to the study done by Zakhama et al, $(r=0.35 \mathrm{p}=0.4)^{17}$.

So, the main result of the present study is the poor relationship between QRS duration and cardiac asynchrony observed by conventional and more sophisticated echocardiographic techniques. Even though it was affirmed by Rouleau et al, who showed a good correlation between IVMD and QRS width $(\mathrm{r}=0.86, \mathrm{p}<0.01), 18$ it failed to show this correlation in this series, this same result had been reported by Ghio in a larger series of dilated cardiomyopathy: despite a significant correlation between interventricular delay and QRS duration $(r=0.66$, $\mathrm{p}<01$ ), a wide scattering of the data around the identity line was observed ${ }^{11}$. This data suggests that, the QRS width appears to be poorly correlated with the presence of inter-V and intra-LV electromechanical asynchrony.

\section{References:}

1. Mair,F.S., Crowley,T.S. \& Bundred, P.E. (1996) Prevalence, aetiology and management of heart failure in general practice. Br J Gen Pract, 46, 77-79.

2. Hobbs,F.D.R.(2002)Unmet need for diagnosis of heart failure: the view from primary care. Heart, 88, 119-121

3. Gaasch, W .H. (1994) Diagnosis and Treatment of heart failure based on left ventricular systolic or diastolic dysfunction. JAMA, 271, 1276-1280.

4. Grossman, W.(2006) Evaluationof systolic and diastolic function of themyocardium. In: Baim, D.S,( eds) Cardiac Catheterization, Angiography, and Intervention, 7 th ed. Baltimore: Williams \& Wilkins, pp315-320

5. Hess, O.M. \& Carol, J.D.(2008) Clinicalassessment ofheart failure.In: Libby, Bonow, Mann, Zipes.(eds). Braunwald's HEART DISEASE, $8^{\text {th }}$ edition. Saunders Elsevier, pp 569-573. 
6. Haque, S.A.(2001) Detection of Left ventricular diastolic dysfunction in firstacute myocardial infarction by Doppler Echocardiography.MD thesis.BSMMU, Dhaka, Bangladesh.

7. Kabiruzzaman, M., Malik, F.N., Ahmed, N., Badiuzzaman, M., Choudhury, S.R.,Haque, T., Rahman, H., Ahmed, M.N., Banik, D., Khan, M.A.M., Dutta, A.K., Sayeed, S., Khandaker, R.K.\& Malik, A .(2010) Burden of Heart Failure Patients in a Tertiary Level Cardiac Hospital. J Bangladesh Coll Phys Surg, 28, 24-29.

8. Islam, K.H.Q., Ali, M.A., Saha, G.K., Gopi, H., Rahman, M.S., Rahman, A.K.M.M., Saha, C.K., Huq ,S.M. (1998) Pattern of heart failure in national institute of cardiovascular diseases (NICVD), Dhaka. Bangladesh HeartJournal, 13 (1), 13-20.

9. Bax, J.J., Molhoek,S.G., Van Ervan,L., voogd, P.J., Somer,S., Boeroma, E., schediz, M.J., Vanderwell, E.E.(2003) Usefullness of myocardial tissue Doppler Echocardiography to evaluate left ventricular dyssynchrony before and after biventricular pacing in patient with idiopathic dilated Cardiomyopathy.AMJ Cardiol,91,94-97.

10. Bader, H., Garrigue, S., Lafitte, S., Reuter, S., Jais, P., Haissaguerre, M., Bonnet, J., Clementy, J.\& Roudaut R.(2004) Intra-left ventricular electromechanical asynchrony A new independent predictor of severe cardiac events in heart failure patients .J Am Coll Cardiol, 43,248-256.

11. Ghio, S., Constantin, C., Klersy, C., Serio, A. ,Fontana , A., Campana , C.\&Tavazzi , L.(2004) ventricular and intraventricular dyssynchrony are common in heart failure patients, regardless of QRS duration. European Heart Journal, 5,571-578.
12. Pitzalis, M.V., Iacoviello. M., Romito, R., Massari, F., Rizzon, B.,Luzzi, G.,Guida, P.,Andriani, A.\& Mastropasqua, F.(2002) Cardiac resynchronization therapy tailored by echocardiographic evaluation of ventricular asynchrony.J Am Coll Cardiol ,40,1615-22.

13. Soliman, O. I .I., Dominic, A.M.J., Theuns ,D.A.M.J., Geleijnse, M.L., Anwar, A.M., Nemes, A., Caliskan, K., Vletter, W.B., Jordaens, L.J.\& Cate, F.J.T.(2007)Spectral pulsed-wave tissue Doppler imaging lateral-to-septal delay fails to predict clinical or echocardiographic outcome after cardiac resynchronization therapy. Europace, 9, 113-118.

14. Kumar,A.\& Goel,P.K(2007) A Study of Ventricular Asynchrony in Patients with Varying QRS Duration and its Correlation with Left Ventricular Function.Indian Heart J, 59(3),256-65.

15. Burri, H. \& Lerch, R.(2006) Echocardiography and patient selection for cardiac resynchronization therapya critical appraisal. Heart Rhythm,3,474-9.

16. Bleeker, G.B., Schalij, M.J., \& Molhoek, S.G. (2004) Relationship between QRS duration and left ventricular dyssynchrony in patients with end-stage heart failure. $J$ Cardiovasc Electrophysiol, 15,544-9.

17. Zakhama,L., Neffati,S., Boussabeh,E., Boukhris,B., Saad,R., Jendoubi,A.\& Youssef, S.B.(2010) Echocardiographic assessment of left ventricular dyssynchrony and correlation with QRS width in chronic heart failure.La tunisie Medicale, 88, 234 -239.

18. Rouleau, F., Merheb, M.\& Geffroy, S.(2001) Echocardiographic assessment of the interventricular delay of activation and correlation to the QRS width in dilated cardiomyopathy. PACE, 24, 1500-6 